\title{
أهمية المرافق والخدمات في الوسط الحضري
}

$$
\begin{aligned}
& \text { نوال نوار } \\
& \text { كلية العلوم الإنسانية و الاجتماعية } \\
& \text { جامعة عبد الحميد مهري } \\
& \text { قسنطينة2(الجز ائر) }
\end{aligned}
$$

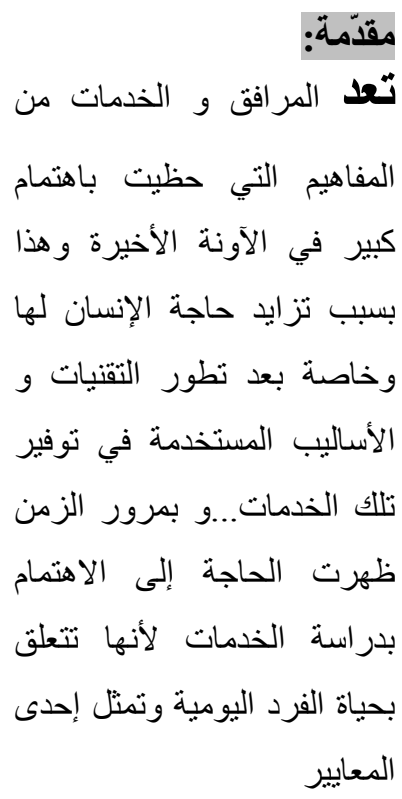

إن انتشار التجهيزات الجماعية على مستوى مختلف أحياء الددن هو أحد

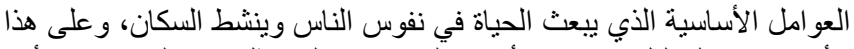

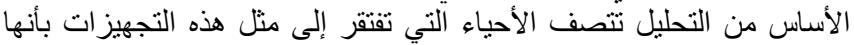

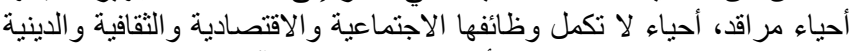

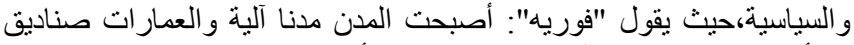
بها أقفاص للاجاج و هي آلذ وظيفتها إنجاب الأطفال فقط.

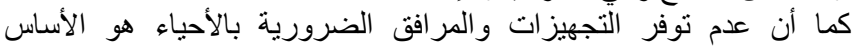

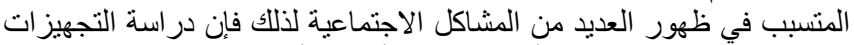

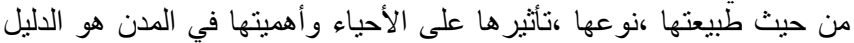

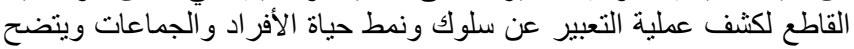

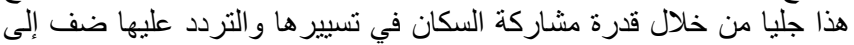

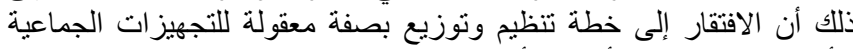

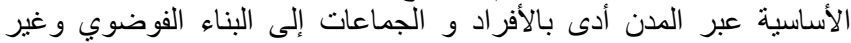

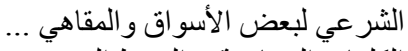

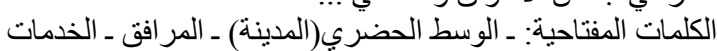

\begin{abstract}
:
The spread of community facilities at the level of the various neighborhoods of the cities is fundamental factors that Brea this life in the hearts of people and active population, and on this basis of the analysis is characterized by neighborhoods that lack such equipment as neighborhoods shrines, neighborhoods do not complement the functions of social, economic and cultural, religious and political,where he says "in stand": cities become cities mechanism buildings and boxes of chick en cages by a machine function having children only. The lack of equipment and facility essences sary neighbor hoods is the foundation causing the emergence of many social problems, so the study of equipment in terms of the nature, type, impact on neighborhoods and their importance in the cities conclusive evidence to uncover the process of expression of the behavior and lifestyle of individuals and groups This is demonstrated through the ability of people's par ticipation in the conduct and the frequency it Add to that the lack of a plant organize and distribute a reasonable basis for collective basic equipment cities across individuals and groups led to chaotic building and some of the illegal markets and cafes...

Keywords :Cites‘ Utilities‘ Services.
\end{abstract}




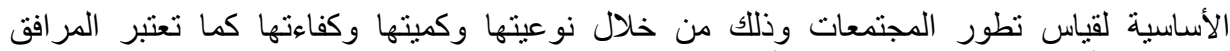

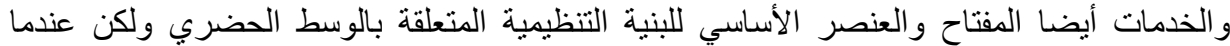

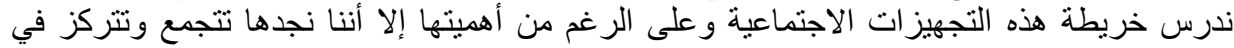

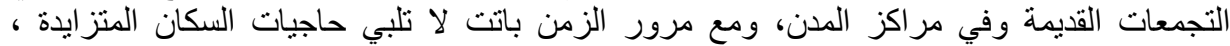

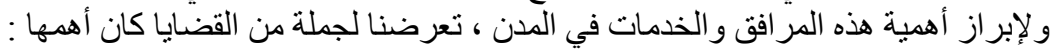

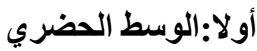

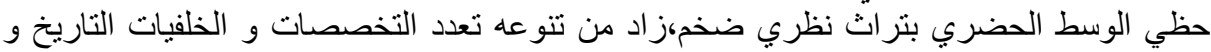

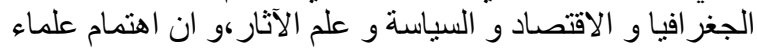

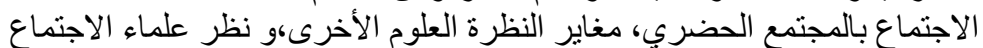

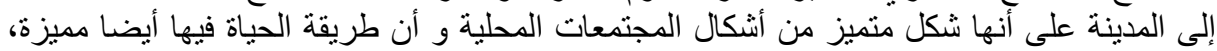
فعكفو ا على دراسة الثقافة الفريدة للمدينة.

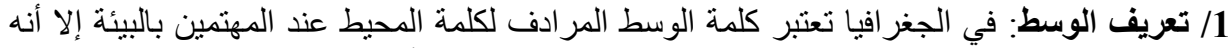

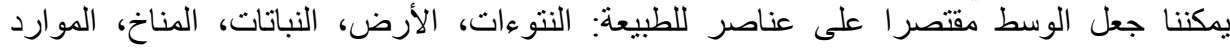

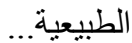

فالوسط بتضمن أيضا البناءات الإنسانية: كالصناعة البنى التحتية والمؤسسات وهكذا نتكلم عن وسط مدني أو وسط صناعي أو وسط حضري البنائ...

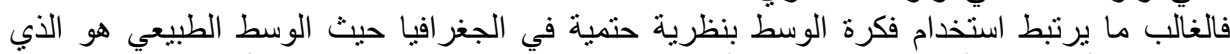

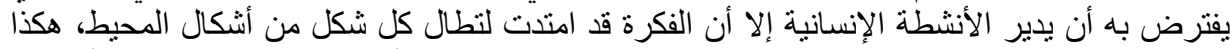

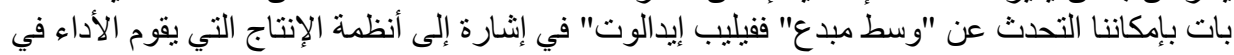

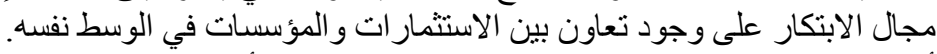

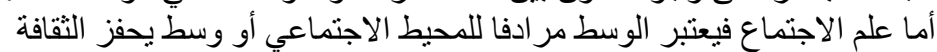

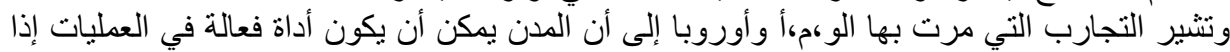

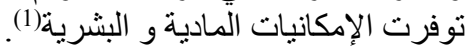

2/ مفهوم الحضري: هو الذئي يستقر بالأمصار و المدن(2). 3/ مفهوم الوسط الحضري:

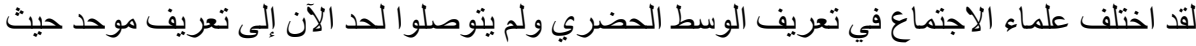

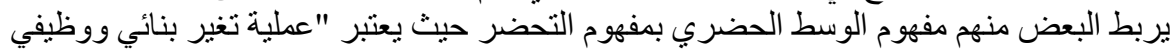

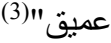
كما ذهب البعض الآخر إلى ربطه بمفهوم المجتمع الحضري و الذي هو مجتمع الدئي المدينة عند علماء

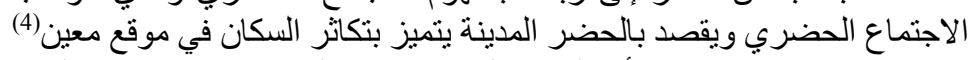
يرى "محمد عاطف غيث "أن الوسط الحضري هو المدينة يتميز بنمط مثالي وعين وعد سكاني كبير وهو

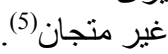

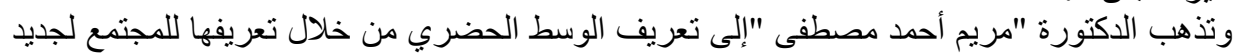

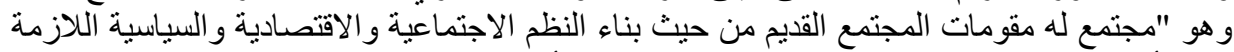

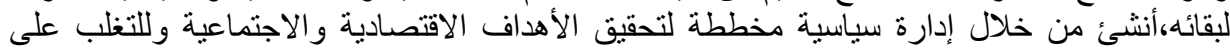

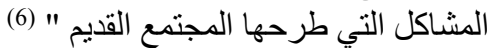

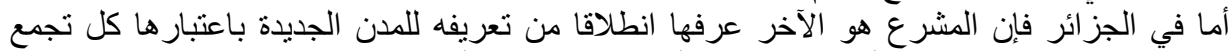

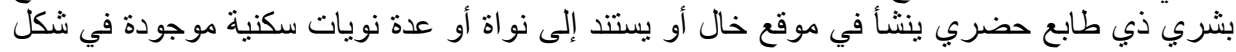

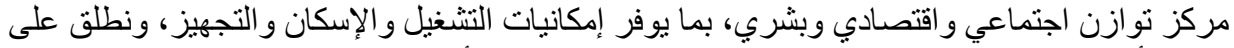

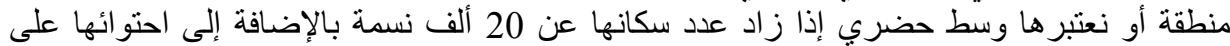
وظائف إدارية وتجارية وصناعيةً (7). 
و الملاحظ من خلال هذه التعاريف أن الحديث عن الوسط الحضري يحمل في طياته حديث عن الددينة

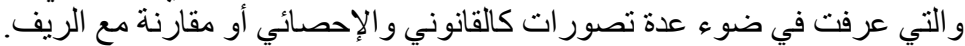

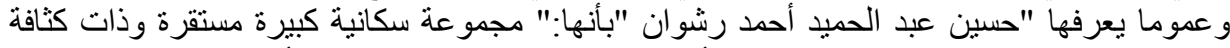

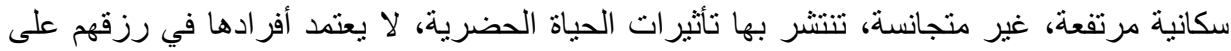

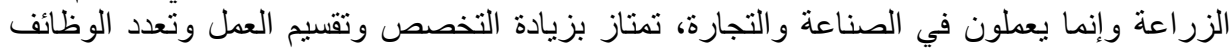

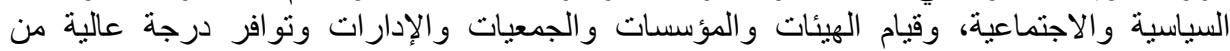

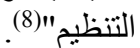

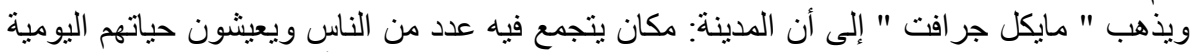

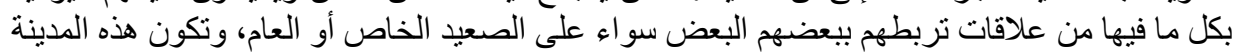

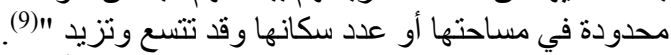

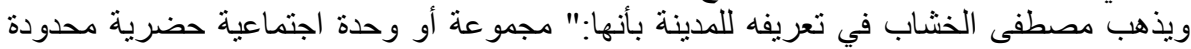

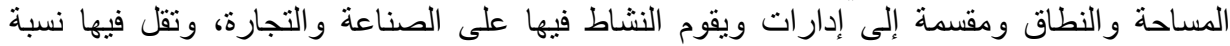

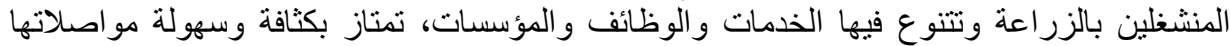

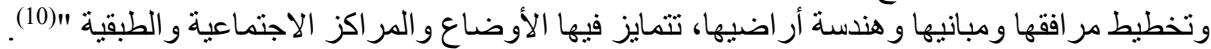

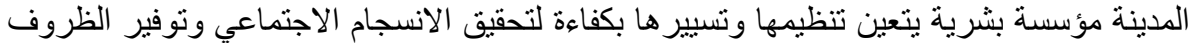

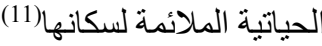

\section{ثانيا: المر افق والخدمات (التجهيزات الجماعية):}

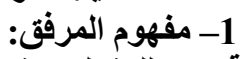

*ثلغة: في اللغة العربية هو من الفعل"رفق" "يرفق " واسم المفعول "مرفقا" ويعني لغة "تابعا". (12)

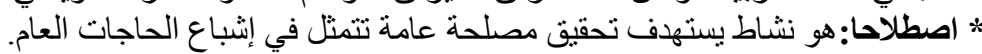

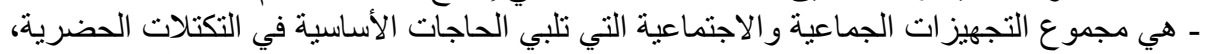

وتتمثل في المباني و الطرق وغير ها حيث تثغل قسما من المجال وتخدم صالح الجماعة. 2 - 2 - 2 تعريف الخدمات:

وردت عدة تعاريف مختلفة للخدمات و هذا حسب وجهة نظر الباحثين المهتمين بهذا المجال ومنها:

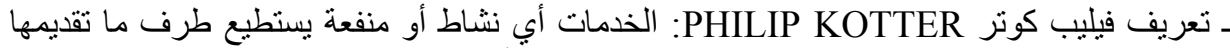

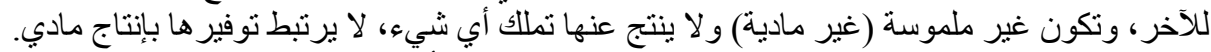

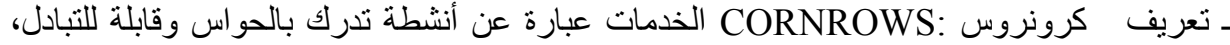
تقدمها شركات أو مؤسسات معينة مختصة بنلاك الخدمات (مؤسسات خدمية).

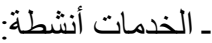

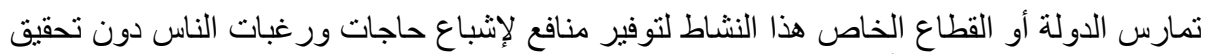

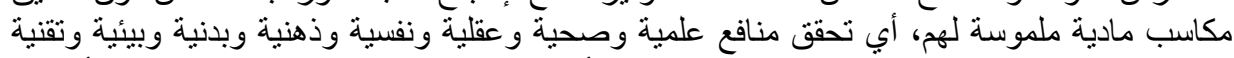

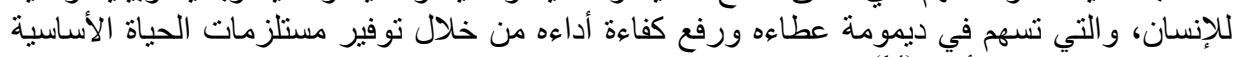
التي تحقق الصحة والأمان. (14)

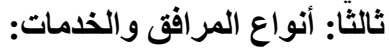

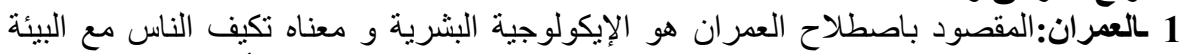

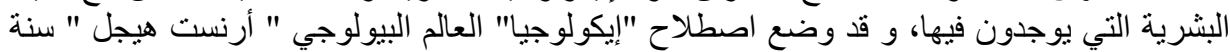

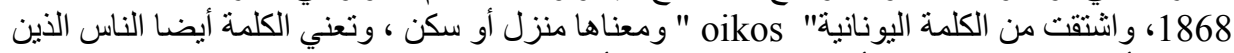
يقطنون أو ينزلون في المنزل أو ينزلون في السكن أو يقيمون في المسكن و نثشاطهم اليومي للدحافظة الئنة

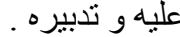
كما وردت عدة تعاريف له تثبر في معناها إلى >> علاقة الإنسان بالبيئة ...، واسم للبنيان ولما يعمر به المكان ويحسن حالته بو اسطة الفلاحة وكثرة الأهالي ونجاح أعمال التمدن >>. (15) 


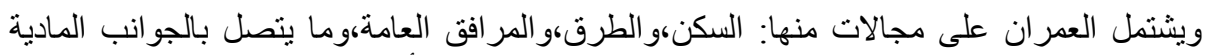

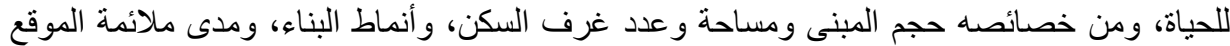

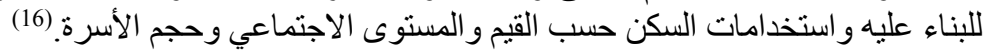

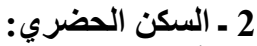

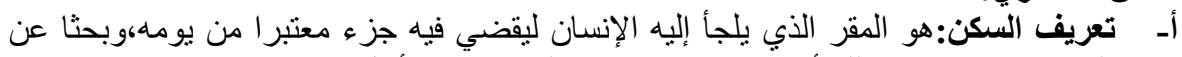

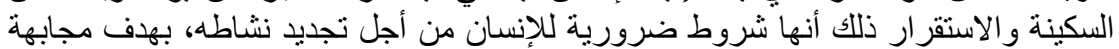

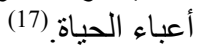

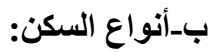
* ألسكن الفردي: وهو الثكل الأول الذي عرفه الإنسان وشيده، وهو بناء أفقي يتطلب مساحة أرضية

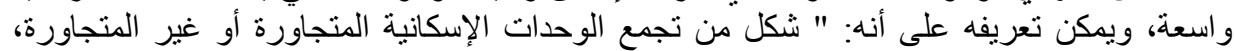

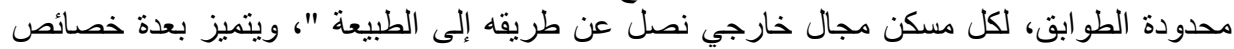

ـ يمنح الحرية لصناحبه بتقسيم مجاله السكني حسب معطيات الأسرة و أفر ادها(18).

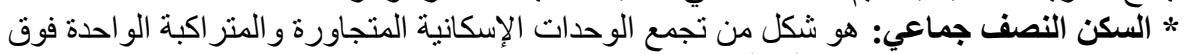

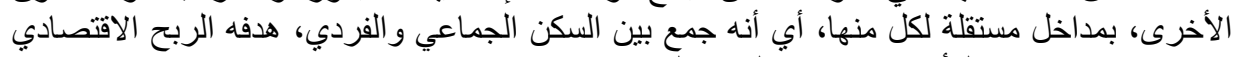

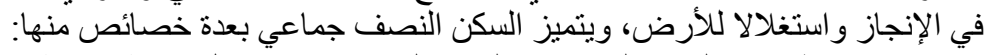

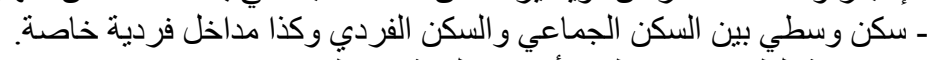

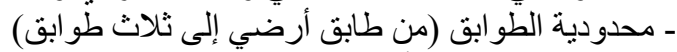

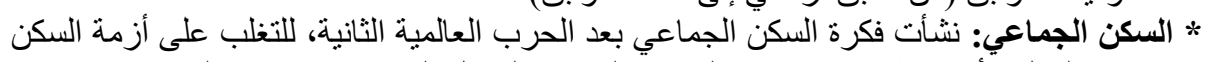

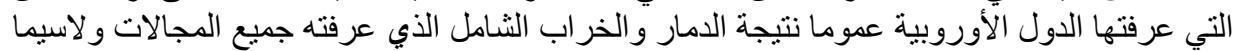

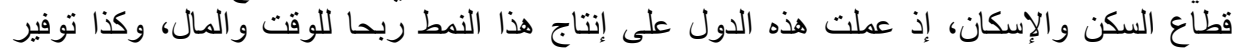
الأراضي واستغلالها في مجالات ألخات أخري.

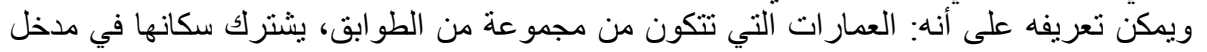

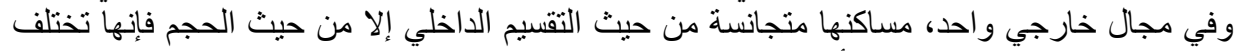
في عدد الغرف، ولَّها عدة نماذج أهمها:

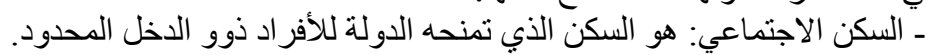

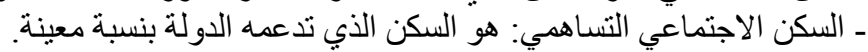

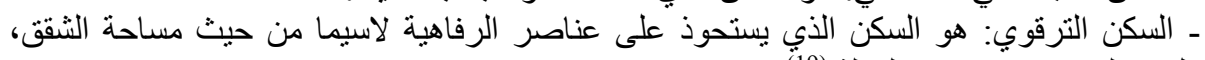

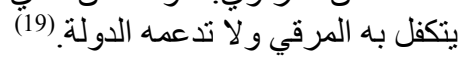

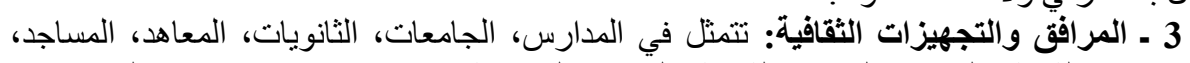

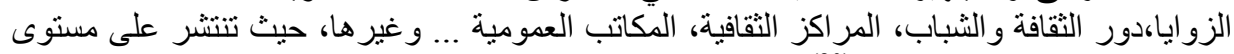

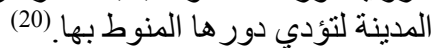
4 ـ المرافق الاقتصادية: تتمثل في الأسو اق الأسبو عية العمومية بهدف قضاء الحاجات اليومية، وكذا المناطق الصناعية المختلفة. (21)

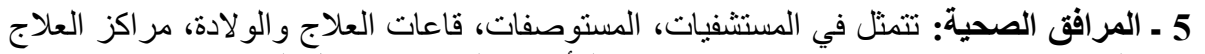

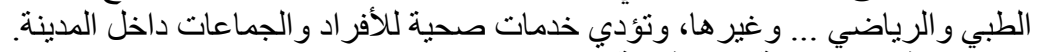

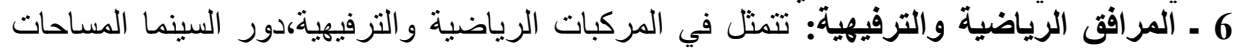

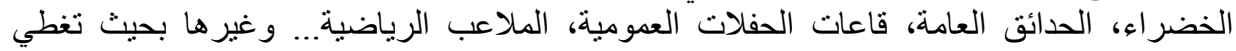
حاجات السكان الرياضية والترفيهية على مستوى المدينة. 
7 ـ المرافق الإدارية: تتمثل في دور البلدية، المكاتب البريدية، مراكز الثرطة، ومختلف الإدارات

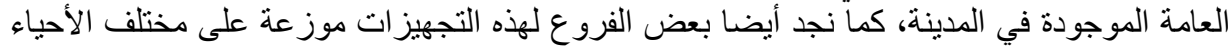

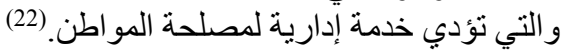
8 ـ طرق النقل والمواصلات:

أتتعريف النقل: يعرف النقل النقل على أنه دورة الأفراد والطاقة والبضائع والخدمات، يقوم بها فاعلون

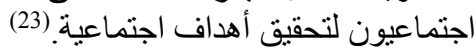

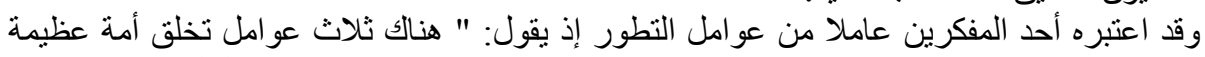

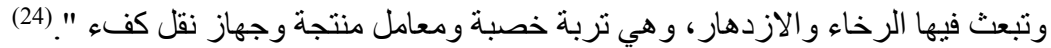

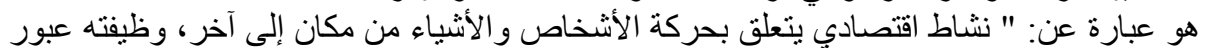

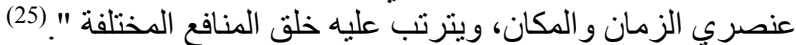

وفي معجم العلوم الاجتماعية فإن اللفظ قد بستخدم للإنشارة إلى خدمة تغيير مكان السلع أو الوان

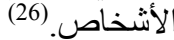

أما بالنسبة للطرق ووسائل النقل فإن استر اتيجية التخطيط لإنشاء المجموعة التهب السكنية بجميع أنواعهاء

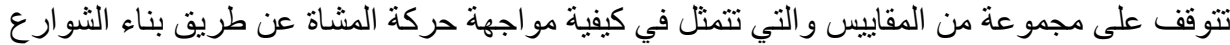

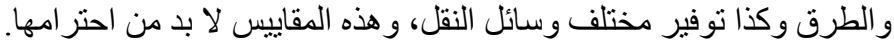
وأما فيما يخص والنقل فيقوم مهندسو النقل بحساب عدد وسائل هذا الأخير (عن طريق قياس حجم النقل

وحركة المرور وكذا ساعات الضغط).

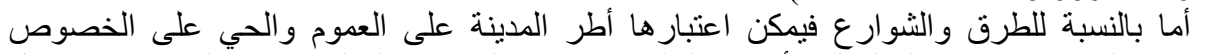

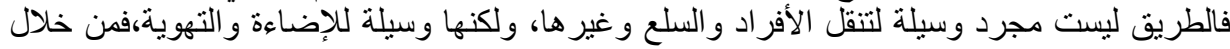
المرسوم التففيذي رقم 175 /91 المؤرخ في 28 /1991/05 و المحدد للقو اعد العامة للتهيئة والتعمير

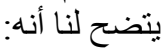

ـ لا بد أن تزود أي مجموعة سكنية بطرق ثانوية لها أدنى حد من الاتصال مع الطرق ذات حركة

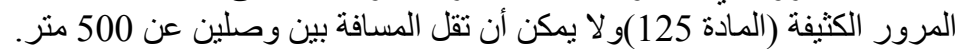

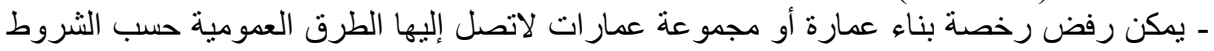

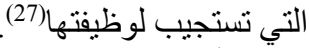

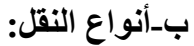

* من حيث الموضوع:ونقصد به نقل البّاع البضائع و الأشخاص سواء داخل المدن أو خارجها أو بين الدول.

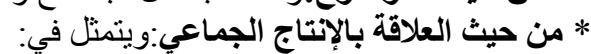
ـ النقل الإنتاجي: ويرتبط مباثرة بالعملية الإنتاجية كنقل أدوات الإنتاج، الماكنات، المعدات، ونقل

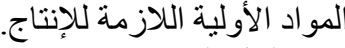
ـ النقل الخدماتي: يتضمن هذا الثنكل تقديم الخدمات في قطاعات الخذمات غير الإنتاجية؛ كالصحة، التعليم و الخدمات المتعلقة بانتقال السكان من مكان لآخر لتحقيق رغبات فئهم.

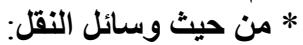

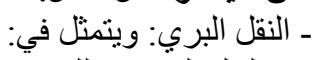

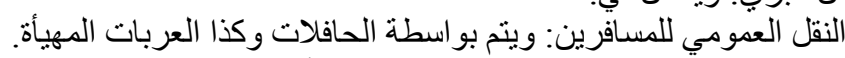

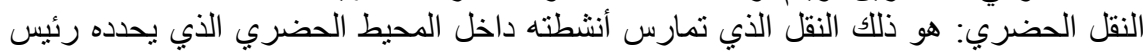

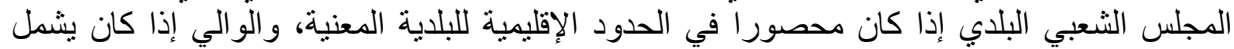

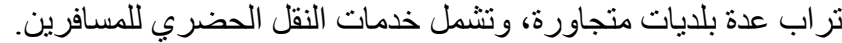

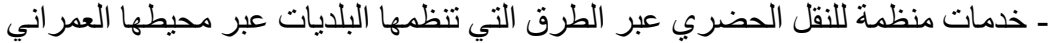

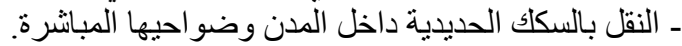

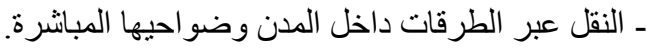
النقل غير الحضري للمسافرين: بشتىل على الخدمات التالية النقل الددرسي، السواح ونقل المرضى النق 
ـ ـ النقل الجوي: يتمثل في الطائرات.

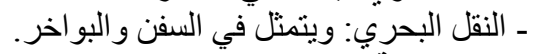

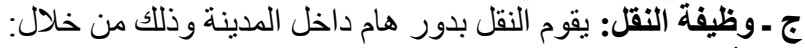

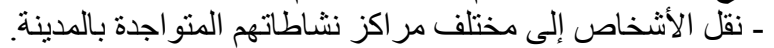

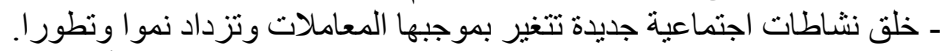

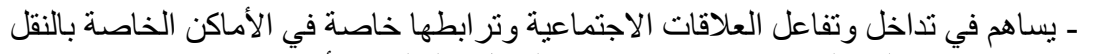

- يربط بين مختلف الطبقات الاجتماعية منها العمال و الطلبة و الأساتذة.

ـ ـ نقل الدداخيل الصناعية و الزر اعية.

ـ تسهيل التنقلات اليومية للعائلات أو التنزه في الأماكن العمومية مثل شواطئ البحر، الغابات

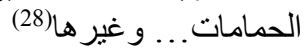

9 ـ الشبكات التقنية:

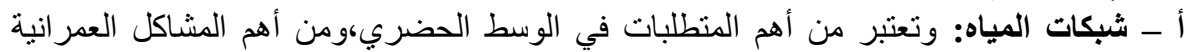

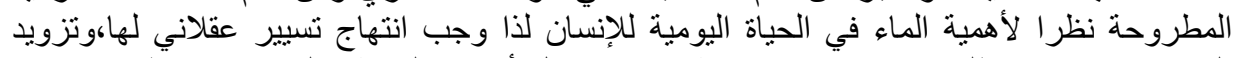

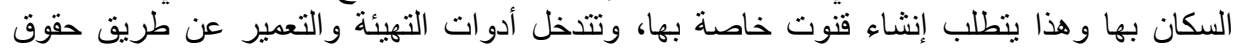

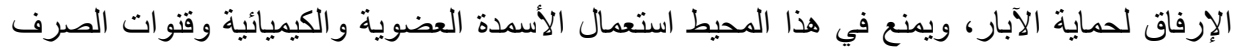

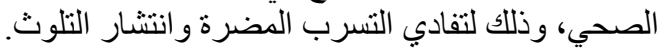

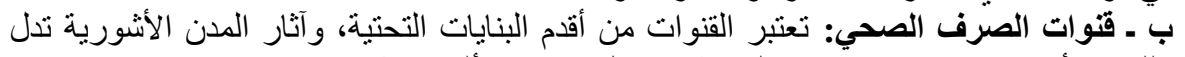

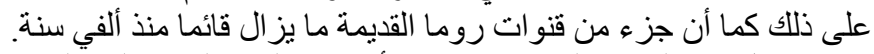

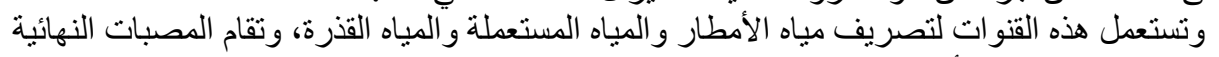

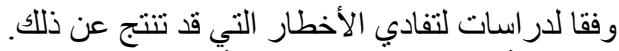

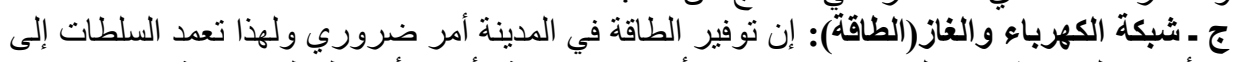

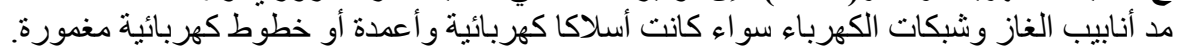

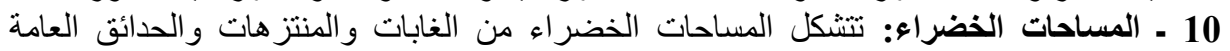

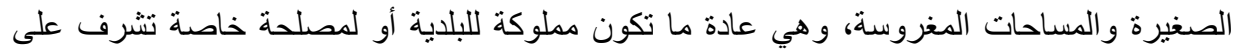

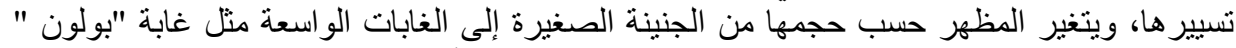

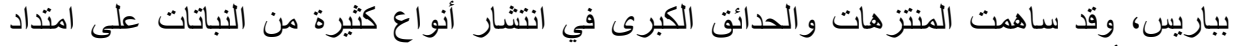
القار ات، أما تهيئتها فهي سهلة و غير المير مكلفة. و المساحات الخضراء تلعب دورا أساسيا في تجميل المحيط الحضري، كما كما أن الأشجار المغروسة

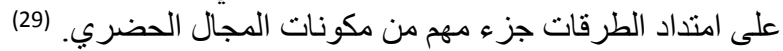

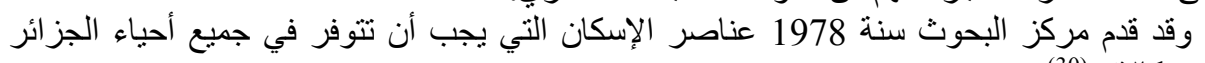

\begin{tabular}{|c|c|c|c|c|c|c|c|}
\hline تجارية & ثقافية & اجتماعية & تربوية & صحية & إدارية & & تاصر الإسكـــان \\
\hline - & - & $\begin{array}{l}- \\
- \\
-\end{array}$ & - & - & $\begin{array}{l}- \\
- \\
-\end{array}$ & الطفولة & 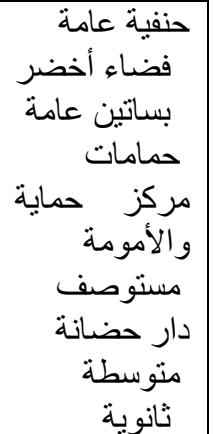 \\
\hline
\end{tabular}




\begin{tabular}{|c|c|c|c|c|c|c|}
\hline - & & & & & & نهانو نجارية تقنية \\
\hline تجارية & ثقافية & اجتماعية & تربوية & صحية & إدارية & تـاصر الإسـكــان \\
\hline $\begin{array}{l}- \\
- \\
-\end{array}$ & - & $\begin{array}{l}- \\
- \\
- \\
- \\
- \\
- \\
- \\
- \\
-\end{array}$ & $\begin{array}{l}- \\
- \\
- \\
- \\
- \\
- \\
-\end{array}$ & & - & 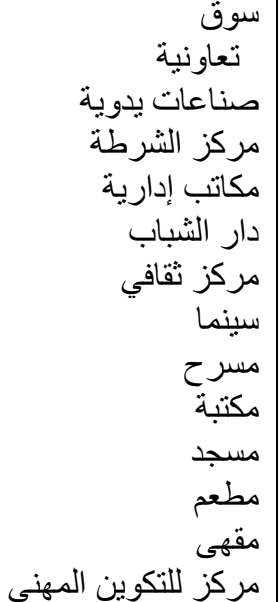 \\
\hline
\end{tabular}

المصدر:عبد الحميد دليمي: دراسة في العمران ـ السكن والإسكان ـ دار الهدى للطباعة والنشر

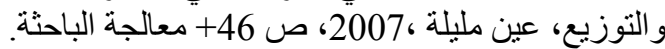
رابعا ـ أهمية المرافق والتجهيزات في المدينة:

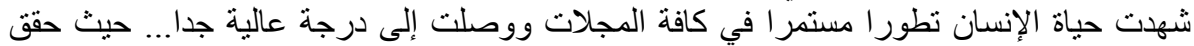

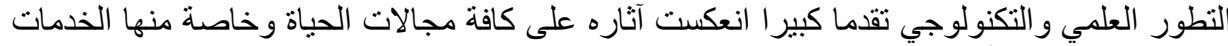

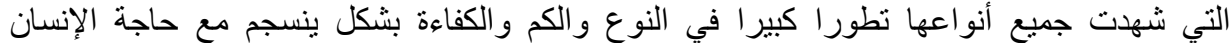

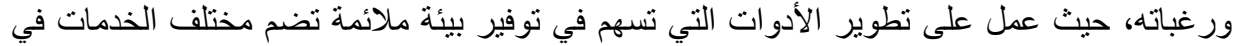

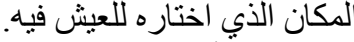

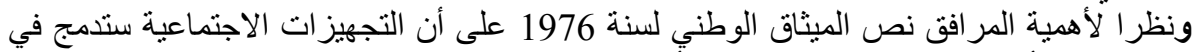

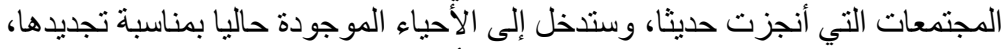

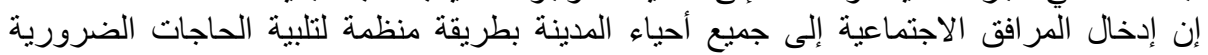

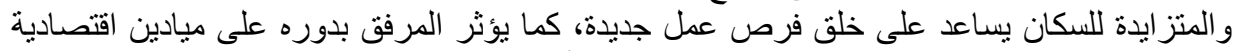

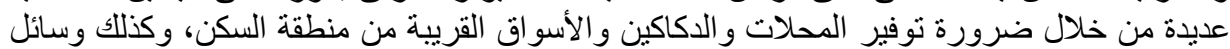

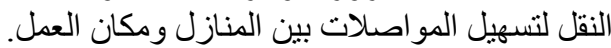

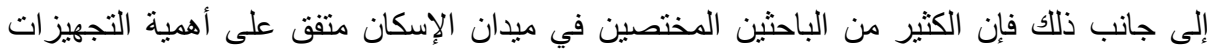

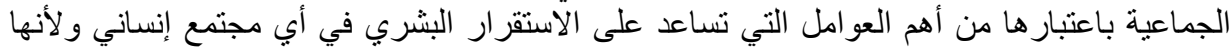

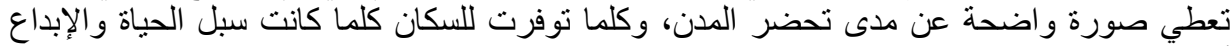

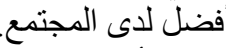

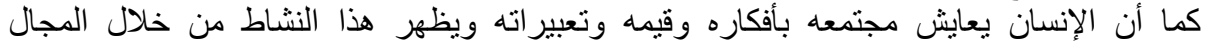

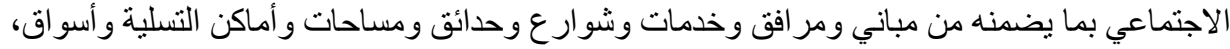
وما ينتجه من تفاعل و علاقات اجتماعية ونماذج بشرية. 


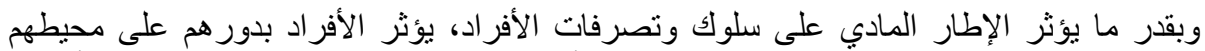

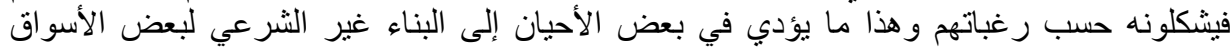

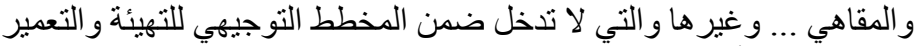

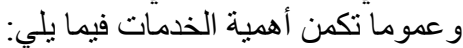

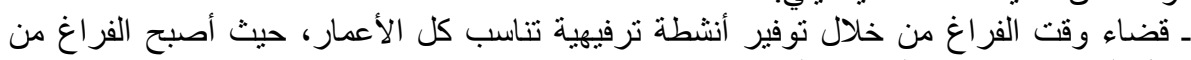
المشاكل التي تو اجه سكان المناطق التهن الحضرية.

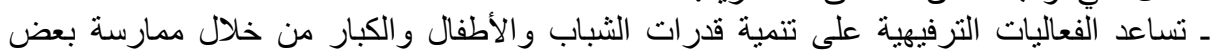

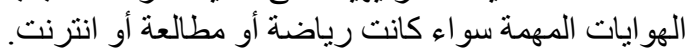
ـ ـ تمثل المناطق الترفيهية مكانا لتعارف أبناء المدينة سواء على التى مستوى الأفر اد أو الجماعات مما يخلق تجانس اجتماعي بين سكان المدينة. ـ تساهم المناطق الترفيهية من الحدائق والساحات المفتوحة في تغيير الظروف المناخية المحلية في

المدينة. ـ تعد الخدمات من الأنشطة التي تحرك النشاط الاقتصادي في المدينة من خلال تقديم عدد من

خاتمة:

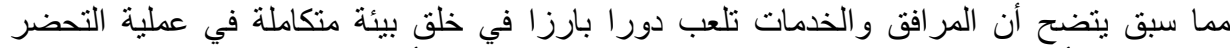

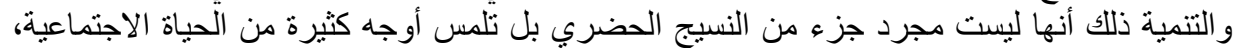

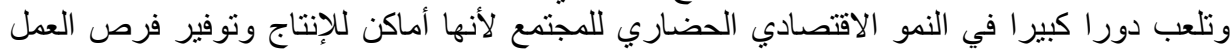

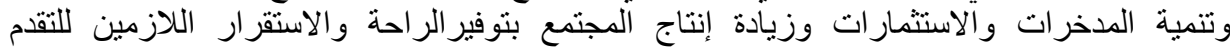

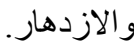

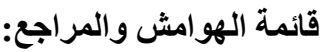

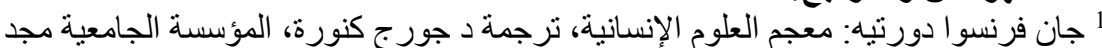

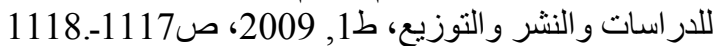
2 سميح غنيم: موسو عة مصطلحات العلوم الاجتماعية و السياسية في الفكر العربي و الإسلامي، مكتبة

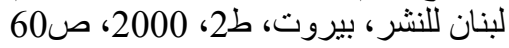

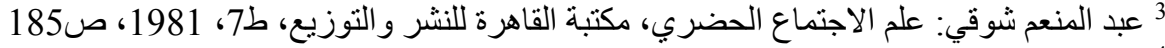

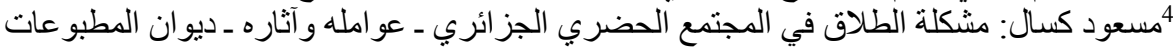

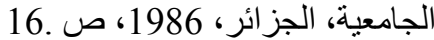
5 محمد عاطف غيث: علم الاجنماع الحضري الئ، ـ مدخل نظري، دار المعرفة الجامعية، الإسكندرية،

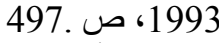
6 د مريم أحمد مصطفى و عبد الله عبد الرحمان: علم اجتماع المجتمعات الحديثة، دار المعرفة الجامعية،

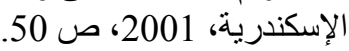
7 المادة (04) من القانون 06 /06 المؤرخ في 20 فبر اير 2006 المنضمن القانون التوجيهي للمدينة 8 حسين عبد الحمبد أحمد رشوان: مشكلات المدينة، المكتب العربي الحديث، الإسكندرية ،2002،

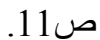
9محمد أحمد غنيم: المدينة، دراسة في الانثروبولوجيا الحضرية، دار المعرفة الجامعية، الإسكندرية،

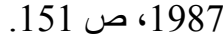
10 مصطفى الخشاب: علم الاجتماع الحضري الأنجلو أمريكي، مطبعة لجنة البيان العربي، القاهرة،

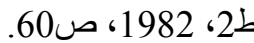

11 بوليفا آسيا: إعادة التقسيم التر ابي لبلدية قسنطينة، جامعة منتوري قسنطينة، 1997، ص .92 
2212 جبر ان مسعود: مجاني الطلاب، دار المجاني للطباعة والنشر و التوزيع، بيروت، ط 4، 1986، ص 288. 13 عبد الحميد دليمي: أزمة الإسكان في مدينة قسنطينة، منشور ات جامعة منتوري، قسنطينة، 2000، 14 خلف حسين علي الدليمي: تخطيط الخدمات و البنية التحتية،دار صفاء للنشر و التوزيع، عمان، ط1،

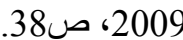

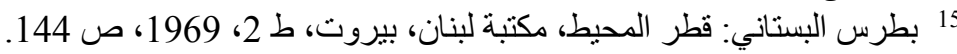
16 عبد الإله عياش وإسحاق يعقوب: الاتجاهات العاصرة في الدراسات الحضرية، وكالة المطبو عات،

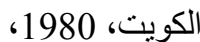

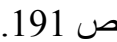
17 أحمد الصبور : المعرفة والسلطة في المجتمع العربي، مركز الدراسات، الوحدة العربية، بيروت،

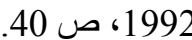
18 محمد حسين: الأسرة ومشاكلها، دار النهضة العربية للطباعة والنشر و التوزيع، بيروت، 1981، ص 19 عبد الحميد دليمي: الو اقع و الظو اهر الحضرية، منشور ات جامعة منتوري، قسنطينة، بدون سنة، ص

20 محمد عبد اللطيف: النظريات المعاصرة للمر افق العامة، منشور ات كلية الحقوق، الكويت، ط 195 ،

دون شريف رحماني: جز ائر الغد " استرجاع التراب الوطني "، ديوان المطبو عات الجامعية، الجزائر،

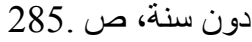
22 دمعار عو ابدي: القانون الإداري، المؤسسة الوطنية للكتاب، ديو ان المطبو عات الجامعية، الجزائر،

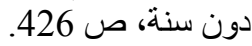
23 السيد عبد العاطي السيد: علم الاجتماع الحضري بين النظرية و التطبيق، دار المعرفة الجامعية،

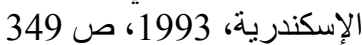

24 عبد الرزاق حسن: المو اصلات في الوطن العربي، مركز الوحدة العربية، بيروت، لبنان، ط 1،

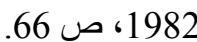

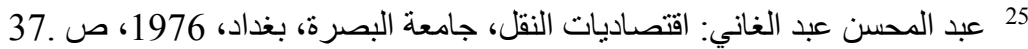
26ابر اهيم مذكور: معجم العلوم الاجتماعي، الهيئة المصرية العامة للكتاب، الاسكندرية، 1975، ص صلئن

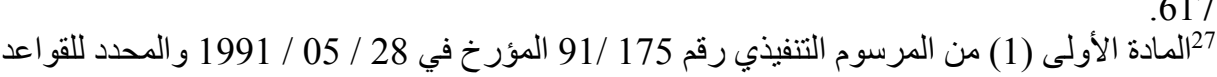

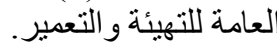

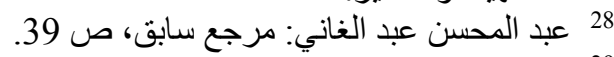

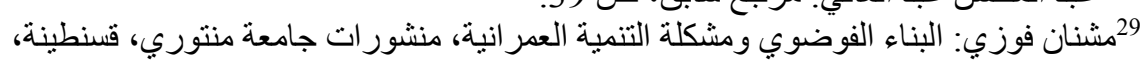

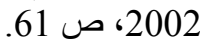
30 عبد الحميد دليمي: در اسة في العمر ان ـ السكن و الإسكان ـ دار الهدى للطباعة و النشر و التوزيع، عين

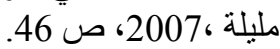
31 خلف حسين علي الدليمي: تخطيط الخدمات المجتمعية، مرجع سابق، ص43 ـ ص 194 - 195. 